\title{
Art And Aggression: A Correlational Study
}

\author{
Anangsha Pathak ${ }^{1}$, Jade Carvalho ${ }^{2}$ \\ ${ }^{1}$ TYBA Psychology, Department of Psychology, K.C. College, Mumbai \\ ${ }^{2}$ Assistant Professor, Department of Psychology, K.C. College, Mumbai \\ Corresponding author: Ms. Anangsha Pathak \\ Email - anangsha.pathak@gmail.com
}

\begin{abstract}
Background: This paper explores the various psychological phenomena, especially those of aggression, that, over the ages, have given rise to paintings which are considered works of worldly geniuses today. The paper studies participants' level of aggressiveness before and after viewing a set of paintings in depth and measures to check whether there is any possible emotive or behavioral change.

Methods: With the administration of the Buss-Perry Aggression Questionnaire (pre-test), followed by exposure to paintings inviting in-depth, elaborative and qualitative responses, The Hostility Questionnaire (post-test) was administered to the participants.

Results: Scores from both the set of questionnaires were correlated to check whether there lay any emotive or behavioral differences between before and after in-depth exposure to the paintings, and the significance of this difference was found out. Thus, exposure to paintings reflecting great negative emotions is expected to provide a change in participants' immediate emotive or behavioral responses.

Conclusion: This finding is of importance for how art is an effective means of channelizing one's feelings that leads to a change or shift in one's current psychological state. Since this has been a locally bound study, experimental evidences would be required to further confirm a causative role of exposure to art and changes in levels of aggression.
\end{abstract}

Keywords: Art, Aggression, Emotive Change, Behavioural difference

(Paper received $-2^{\text {nd }}$ January 2018, Peer review completed $-6^{\text {th }}$ January 2018)

(Accepted $-10^{\text {th }}$ January 2018)

\section{INTRODUCTION}

Art, in any form, is so much a part of our lives. As a medium, art has the power to communicate universally across all barriers and it is here that so many of what humankind has been through is portrayed in its guises - in paintings we see everything from outcries of war and roaring revolutions to inner conflicts which have turned into "madness" and splashed on the canvas. An era of art, called Expressionism, deals with exactly this. According to Wikipedia, "Expressionism was a modernist movement, initially in poetry and painting, originating in Germany at the beginning of the 20th century. Its typical trait is to present the world solely from a subjective perspective, distorting it radically for emotional effect in order to evoke moods or ideas [1]. Expressionist artists sought to express the meaning of emotional experience rather than physical reality" [2].

The paper looks at psychological phenomena and its manifestation in visual art. Stalwart paintings like The Scream by Edvard Munch, Guernica by Pablo Picasso, and The Face of War by Salvador Dali reflect an upsurge of emotions that result into some form of psychological phenomena, leading to the making of such masterpieces. Interesting anecdotes of artists like that of Vincent Van Gogh who cut his ear off as to symbolize an end to a fight with friend and French artist, Paul Gauguin, intrigue me. The next day, as if 
nothing changed, he began painting with a bandage over his ear. Throughout his life, several psychodynamic factors may have contributed to his art work. "...Psychoanalyst Sigmund Freud viewed art as a privileged form of neurosis where the analyst-critic explores the artwork in order to understand and unearth the vicissitudes of the creator's psychological motivations. In this context van Gough's art represent a deep psychological sketch. He left a profound, soul-searching description of his jagged life in his art work" [3]. He was later diagnosed with a tendency to engage in self-destruction that led to him committing suicide.

The paper looks at paintings especially which have led researchers to deduce that their painters were sufferers of mental illnesses, displaying abnormal behaviour in their lives. These paintings and their effects on viewership is studied, measuring participants' level of aggressiveness before and after viewing a set of paintings in depth to check whether there is any possible emotive or behavioural change. With the administration of the Buss-Perry Aggression Questionnaire (pre-test), followed by exposure to paintings inviting elaborative and qualitative responses, The Hostility Questionnaire [4] (post-test) was administered to the participants. Scores from both the set of questionnaires were calculated to check the difference and its significance was found out.

Art and emotion have since long been understood to be closely linked to each other. Art, in fact, is said to be a good way to channel one's emotion. To look at it another way, paintings also have the power to portray those emotions and project it on to the viewer who is affected by the same. In a specific study, "it has been discovered that the use of a specific shade of pink can have a moderating effect on subjects experiencing feelings of anger or agitation. The calming effect of pink if appropriately applied, relaxes hostile or agitated behaviour in approximately ten to fifteen minutes" [5-6].

Art and mental illness are said to be correlated. "Artwork and psychiatric disorders are often linked. Accomplished artists with psychiatric disorders express themselves and their emotional distress through their works, and art therapists use the visual arts to help clients understand their problems and cope with them" [7]. "The thoughts, beliefs, values, and emotions of artists are inescapably represented in their work - and on some occasions, intentionally depicted. (One) of the more familiar connections between art and the functions of the mind are the ways in which artists express their own thoughts, feelings, and mental distress in their paintings..." [8].

Painters like Franz Marc, Amedeo Modigliani, and Erich Heckel have led lives of unaccountable distress that is revealed clearly in their paintings. One of the most prominent emotions portrayed is that of aggression. The crux of the paper lies in exposure to a set of such paintings and analysing aggressive behaviour before and after participants have provided in-depth qualitative responses.

Aggression has been tested with the Buss-Perry Aggression Questionnaire (BP-AQ) as a pre-test measure. Negative emotions and the three basic stress emotions in particular (anxiety, aggression and frustration) have been tested as a post-test measure with The Hostility Questionnaire [4].

\section{METHODOLOGY}

The aim of the paper was to explore the links between paintings as a visual means of portraying art and its effect on aggression.

The hypothesis was that there would be a difference in the level of aggression pre and post exposure to paintings between participants who were shown paintings with high aggressiveness and those shown paintings without high aggressiveness.

The independent variable was the set of paintings which were of two types - ones with a high content of aggressiveness and ones without a high content of aggressiveness.

The dependent variable was change in the level of aggression pre and post exposure to the paintings, measured by the Buss-Perry Aggression Questionnaire (pre-test) and The Hostility Questionnaire (posttest). The scale of measurement was the ratio scale.

Experiment-related controls

All participants were given the same pre-test and post-test questionnaires to fill by themselves. Each participant was either exposed to a set of 4 paintings which were high on aggressive content or a set of 4 paintings which were not high on aggressive content. 
Every participant was asked a list of 10 conversational questions during the exposure of each painting that invited qualitative, in-depth and analytical responses.

\section{Participants}

The sample consisted of 30 participants ( 6 males and 24 females) between 19-21 years of age through snowballing and randomisation techniques. As such, the participants hailed from diverse backgrounds, native languages, native states and religion. Half of them (15) were in the control group (those who were shown "neutral" paintings) and half of them (15) in the experimental group (those who were shown "aggressive" paintings). All participants gave their consent prior to the data collection.

\section{Measures}

Aggression was measured in pre-test by the Buss-Perry Aggression Questionnaire.

The Buss-Perry Aggression Questionnaire was designed by Arnold Buss and Mark Perry, the University of Texas at Austin in a 1992 article for the Journal of Personality and Social Psychology [8].Participants rank certain statements along a 5-point continuum from "extremely uncharacteristic of me" to "extremely characteristic of me." The scores are normalized on a scale of 0 to 1 , with 1 being the highest level of aggression. The BPAQ has 29 items, subdivided in four factors (which resulted from factor analysis): Physical aggression, Verbal aggression, Anger, Hostility

The post-test questionnaire administered was The Hostility Questionnaire. Cynicism, anger, and aggression are the three categories that accurately measured harmful hostility on the Hostility scale. A total score of 0 - 10 indicates a low level of aggression and any score above that indicate a moderate to high level of aggression.

For statistical calculations and data analysis, the Mann-Whitney $U$ test for sample size 30 was used to find out the significance of the difference between the two groups.

\section{Procedure}

A pilot study was conducted on 3 participants and after obtaining desired results, the main data collection began. Participants took a minimum of 90 - 120 minutes for the exposure and analyses of the paintings, providing in-depth and qualitative responses for 10 questions each of the 4 paintings. The pre-test and posttest questionnaires were administered to them which they filled by themselves. After the questionnaires were returned to the author, the participants were thoroughly debriefed which went on for more than a 150 minutes in cases where participants showed great fascination for the study.

The questionnaires were individually scored (with categorical scoring that was meant for individual assessment) and total scores of both the questionnaires were recorded. The significance of the difference will be calculated.

\section{RESULTS}

The findings of the experiment were in line with the hypothesis. The scores of pre-test from both the groups (CG and EG) were compared and the difference between them was calculated. To check whether this difference was statistically significant, a Mann-Whitney U test was carried out.

For a two-tailed (alternative non-directional) hypothesis, the $U$-value is 59 . The critical value of $U$ at $p<$ 0.01 is 51 . Therefore, the result is not significant at $\mathrm{p}<0.01$.

Also, the Z-Score is 2.19834. The p-value is 0.0278 . The result is not significant at $p<0.01$. The two groups are equated on the baseline test of aggression and therefore, the comparison of their mean post-test scores will be valid.

For a one-tailed (alternative directional) hypothesis, the $U$-value is 59 . The critical value of $U$ at $p<0.01$ is 56. Therefore, the result is not significant at $\mathrm{p}<0.01$.

The Z-Score is 2.19834 . The $p$-value is 0.0139 . The result is not significant at $p<0.01$.

In other words, the two groups are equated on the baseline test of aggression and therefore, the comparison of their mean post-test scores will be valid. 
Similarly, the post-test scores from both the groups (CG and EG) were compared and the difference between them was found out. With the help of a Mann-Whitney U test, the statistical significance of the difference was calculated.

For a two-tailed (alternative non-directional) hypothesis, the $\mathrm{U}$-value is 41 . The critical value of $\mathrm{U}$ at $\mathrm{p}<$ 0.01 is 51 . Therefore, the result is significant at $\mathrm{p}<0.01$.

The Z-Score is 2.94494. The p-value is 0.00328 . The result is significant at $p<.01$. This show that the difference between the two groups in the post-test is statistically significant at 0.01 level. For a one-tailed (alternative directional) hypothesis, the $U$-value is 41 . The critical value of $U$ at $p<.01$ is 56. Therefore, the result is significant at $\mathrm{p}<0.01$.

The Z-Score is 2.94494 . The $p$-value is 0.00164 . The result is significant at $p<0.01$.

This show that the difference between the two groups in the post-test is statistically significant at 0.01 level.

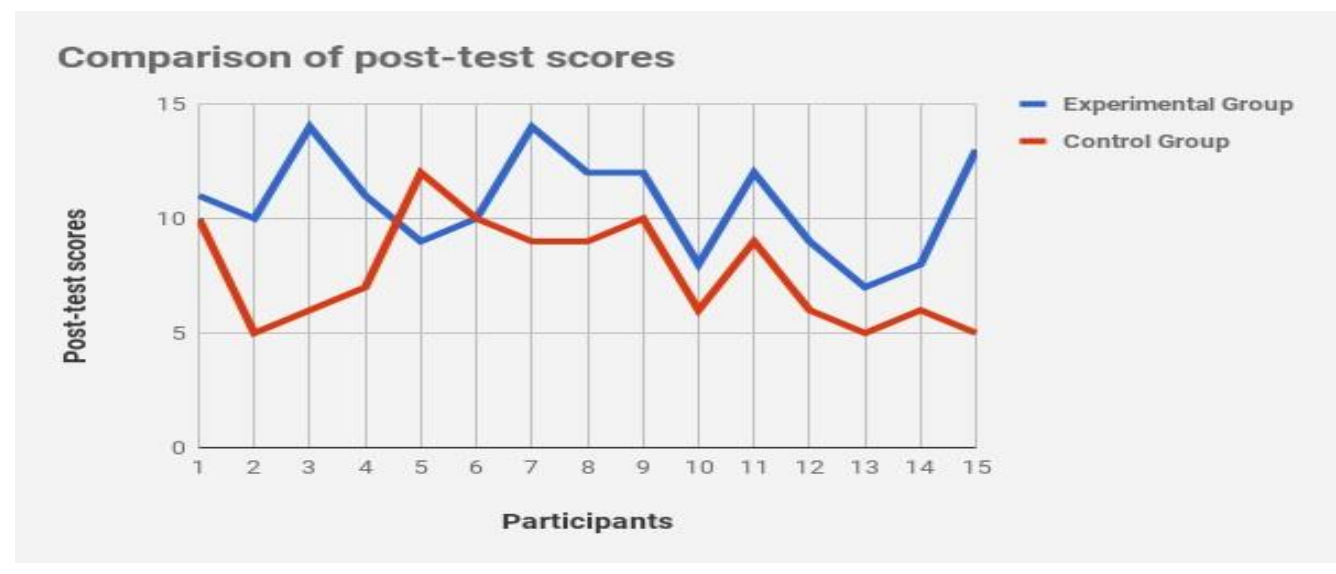

Comparison of post-test means

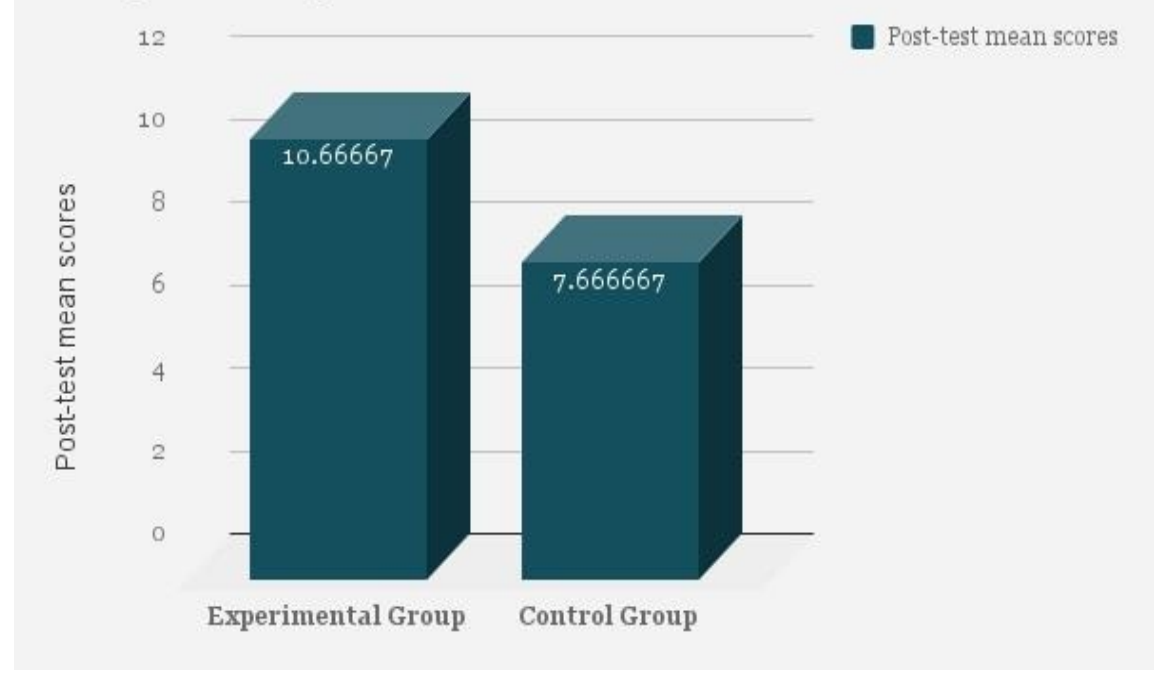

\section{QUALITATIVE ANALYSIS}

Participants who viewed paintings that were aggressive reported some blatant statements like "Take this picture away, I don't want to look at it", "I am sure that I will dream about this tonight" and most of them analysed the paintings with dilated pupils, suggesting a continuous state of high emotional arousal. This set of paintings was often associated with night time as opposed to morning; noon and early evening for the set of "neutral" paintings. Thirdly, these paintings were mostly associations with death, unpleasant 
memories that participants personally connected with, whereas the neutral ones were comparatively "happier" in appearance and induced more positive associations.

All participants were shown both the sets of paintings in debriefing and asked to interpret them however they wanted. It was almost as if the neutral ones were a relief for the participants after analysing the aggressive set. Many also linked these paintings with dark-tale characters like grim fairness, killings and bloodshed (especially for Guernica), scary godmothers plotting to kill someone they know. Another point that surfaced during the administrations was that participants reported that they would be more comfortable to draw the "neutral" paintings themselves, compared to the "aggressive" ones. When asked why, they said that the colours were brighter and evoked more positive feelings - "it feels nice looking at them".

\section{DISCUSSION}

The EG had higher scores of aggression than the CG after exposure to the paintings. Participants found that the dark yet loud colours, confident brushstrokes and vivid, prominent features made the effects of aggression long-lasting. This means that the violent and crass emotions depicted in the paintings really had an effect on participants' present emotional state.

The study can replicated with a bigger sample and in different locations. The author believes that the sample characteristics should not be a cause of deep concern in terms of the variables being measured, since it takes into consideration the intensity of psychological characteristics rather than their nature. Thus, someone belonging to a particular ethnic background might feel the same amount of anger for an event in their context as someone from a different cultural background in their respective context. Moreover, differences among samples of varied backgrounds can be identified based on the qualitative analysis of the responses.

One's social position could determine how items in the questionnaires were perceived. For example, an item "A teenager drives by my yard with the car stereo blaring acid rock" might be difficult for participants of 19 years of age to judge because they might have certain assumptions or possibly even be biased about their contemporaries as well as older adults, which may reflect on the scores.

Although the sample consisted of participants who spoke English as their first or second language, language barriers would have to be taken into consideration. There were instances where some items in the questionnaires were worded in ways that isn't the conventional English one comes across daily - for example, "Sometimes I fly off the handle for no good reason", "At times I feel I have gotten a raw deal out of life" and "Other people always seem to get the breaks."

Further research for this paper will bring in more samples, thus opening up the possibility of finding the data to be statistically significant at a higher level. Psychological characteristics other than aggression can also be analysed, such as one's personality traits, social and personal circumstances that might lead them to perceive art in a unique way, etc.

\section{CONCLUSION}

It is, thus, the author's conclusion that exposure to art plays a significant role in setting the psychological basis for one's immediate emotive and behavioural responses. In this case, levels of aggression were found to have increased after associating and connecting events of one's own life with the paintings shown. This finding is of importance for how art is an effective means of channelizing one's feelings that leads to a change or shift in one's current psychological state. Since this has been a locally bound study, experimental evidences would be required to further confirm a causative role of exposure to art and changes in levels of aggression. However, in order to holistically understand how one registers and perceives art in the form of paintings, several more social factors like one's social location will have to be taken into account, with study and research in terms of richer qualitative analyses responses from a larger sample. 


\section{REFERENCES}

1. Thompson B. Archived at the Wayback Machine. 2010.

2. Tejera V. Art and Human Intelligence. 1966; 85-140.

3. Jayatunge S, Ruwan M. Psychological Reflections of Vincent Van Gogh's Art, Daily News. 1998.

4. Williams R. Anger kills: seventeen strategies for controlling hostility that can harm your health. Crown 2012, Nov 14

5. Schauss AG. Tranquilizing effect of color reduces aggressive behavior and potential violence. J Orthomol Psychiatry 1979;8(4):218-21.

6. Rustin TA. Using artwork to understand the experience of mental illness: Mainstream artists and Outsider artists. GMS Psycho-Social Medicine 2008;5:30-6.

7. Buss AH, Perry M. The aggression questionnaire. J Perosonal Soc Psychol 1992;63(3):452-8.

8. Caine TM, Foulds GA, Hope K. Manual of the hostility and direction of hostility questionnaire. University of London Press; 1967.

\section{RECOMMENDED READING}

1. Gerevich J, Bácskai E, Czobor P. The generalizability of the buss-perry aggression questionnaire. Int J Methods Psychiatr Res 2007;16(3):124-36.

2. Kleinschmidt HJ. The angry act: The role of aggression in creativity. American Imago 1967;24(1):98106.

3. Pezenhoffer I, Gerevich J. Trait-aggression and suicide of Vincent van Gogh. Psychiatria Hungarica: A Magyar Pszichiatriai Tarsasag tudomanyos folyoirata 2015;30(2):201-9.

4. Paleni A, Curri S. Biological aggression of works of art in Venice. In Biodeterioration of materials. Proceedings of the 2nd international biodeterioration symposium. Lunteren, the netherlands, 13th-18th september 19711972 (pp. 392-400). Applied Science Publishers Limited.

5. Cupchik GC, Winston AS, Herz RS. Judgments of similarity and difference between paintings. Visual Arts Research 1992;1:37-50.

6. Manning TM. Aggression depicted in abused children's drawings. The Arts in Psychotherapy. 1987;14(1):15-24.

7. Konečni VJ, Sargent-Pollock D. Arousal, positive and negative affect, and preference for Renaissance and 20th-century paintings. Motivation and Emotion 1977;1(1):75-93.

8. Weisberg RW. On structure in the creative process: A quantitative case-study of the creation of Picasso's Guernica. Empirical Studies of the Arts 2004;22(1):23-54.

9. Kemp SW, Cupchik GC. The emotionally evocative effects of paintings. Visual Arts Research 2007;1:72-82.

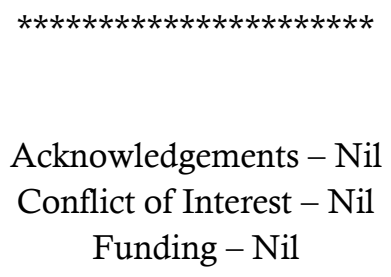

